\title{
Environmental Taxation: Privatization in an International Duopoly with Tariffs
}

\author{
Fernanda A. Ferreira and Flávio Ferreira* \\ Applied Management Research Unit (UNIAG), ESHT - Polytechnic Institute of Porto, Rua D. Sancho I, 981, 4480-876 Vila do Conde, \\ Portugal
}

Received: 17 Apr. 2016, Revised: 10 Oct. 2016, Accepted: 13 Oct. 2016

Published online: 1 Jan. 2017

\begin{abstract}
In this paper, we study trade and environmental policies in an international duopoly serving two countries, with pollution abatement. This analysis is done in both mixed and privatized markets. The model has two stages: First, governments choose environmental taxes and import tariffs, simultaneously; then, the firms compete in the market by choosing output levels for the domestic market and to export and also abatement levels. We analyse the effects of privatization, and we also compare the results obtained in the international competition with the ones got in a domestic competition.
\end{abstract}

Keywords: Industrial Organization; Game Theory, Cournot model, environment, privatization

\section{Introduction}

Markets wherein public and private firms compete can be seen in several industries across different countries. Industries such telecommunications, electricity, natural gas, airlines industries, as well as services including hospitals, banking and education are good examples. Fjell and Heywood [4] analyzed a mixed market in which a state-owned public firm competes as a Stackelberg leader with domestic and foreign private firms. Pal and White [7] studied the interaction between privatization and strategic trade policies, by considering two instruments: a domestic production subsidy and an import tariff. Serizawa [8] analyzed how different types of trade policies affect welfare and compared welfare under combinations of different policies in an international competition.

Some environmentalists argue that increases international trade can damage the environment. Wang and Wang [10] explored whether privatization improves (or deteriorates) the environment in a mixed duopolistic framework with differentiated goods and pollution abatement. They showed that, if the public firm is privatized, less attention is paid to pollution abatement by all the firms coupled with less environment taxes levied by the government, and the environment is more (less) damaged when the goods are less (more) substitutable. Ferreira and Ferreira [2] examined the same questions as in Wang and Wang's paper, by considering a Stackelberg-type sequential-move game.

Tomaru [9] investigated how decision-making upon cost-reducing $R \& D$ investment by a domestic public firm is affected by privatization and entry of a foreign firm. The author showed that privatization deteriorates domestic social welfare. Matsumura and Matsushima [5] showed that privatization of the public firm can improve social welfare.

Ohori [6], studying the interaction between privatization, environmental policy and international trade, showed that policies of privatization can affect the environmental quality. The model considered is a mixed duopoly with a public firm in a domestic country and a private firm in a foreign country, competing in both markets. The model incorporates environmental taxes and import tariffs.

Ferreira and Ferreira [3] did a similar analysis as done by Wang and Wang [10], but, following Ohori [6], they considered that the public firm aims to maximize the social welfare, instead of the sum of consumer surplus and the firm's profit.

The model that we will consider follows Ohori [6] with the following differences: instead of a linear cost function, we consider a quadratic cost function; we introduce abatement levels; our objective function of the public domestic firm is the sum of consumer surplus and

\footnotetext{
*Corresponding author e-mail: fff@esht.ipp.pt
} 
the firm's profit, instead of the social welfare (see Wang and Wang [10]).

An extended abstract of a previous version of this paper was published in the Proceedings of the $12^{\text {th }}$ International Conference on Numerical Analysis and Applied Mathematics (see [1]).

The remained of the paper is organized as follows. In Section II, we present and discuss the mixed model. Section III deals with the privatized model. Section IV yields the main result gained by a direct comparison between both the mixed and privatized models. In Section $\mathrm{V}$, we compare international and domestic competitions. Conclusions are presented in Section VI.

\section{The model}

Consider two countries. The government of each country imposes an environmental tax $t$ to control pollution and a tariff $\mu$ to regulate an imported good. A monopolistic firm in each country, concurrently provides a homogeneous good for the home and foreign markets. The firms are assumed to generate one unit of pollution per unit of output. The quantity produced by the firm $F_{i}$, with $i=1,2$, is $y_{i}=h_{i}+e_{i}$, where $h_{i}$ and $e_{i}$ denote the quantities produced by firm $F_{i}$ for the domestic and foreign markets, respectively. We assume that the domestic firm $F_{1}$ is a public firm, and the foreign firm $F_{2}$ is a private firm. Firm $F_{1}$ 's aim is to maximize the sum of consumer surplus and the firm's profit, while the objective of the foreign firm is to maximize its own profit. Consumers in each country buy the good in the domestic market. The total consumption in country $i$ is $q_{i}=h_{i}+e_{j}$, with $i=1,2$ and $i \neq j$. The inverse demand function is given by

$$
p_{i}=\alpha-q_{i}=a-\left(h_{i}+e_{j}\right),
$$

where $\alpha>0$ represents the choke price. In this paper, we assume that both firms have identical technologies and the production cost function takes a quadratic form: $C\left(y_{i}\right)=$ $F+y_{i}^{2}$, where $F=0$ without loss of generality. The total consumer surplus in country $i$ is

$$
C S_{i}=\frac{1}{2}\left(h_{i}+e_{j}\right)^{2} .
$$

The production of the good by firm $F_{i}$ leads to pollution $d_{i}$. Environmental damage function is given by

$$
E D_{i}=\frac{d_{i}^{2}}{2} .
$$

However, each firm can prevent pollution by undertaking abatement measures. Suppose that if firm $F_{i}$ chooses pollution abatement level $a_{i}$, then the corresponding emission level is $d_{i}=y_{i}-a_{i}$. The cost of pollution abatement of firm $F_{i}$ is $a_{i}^{2} / 2$.

In each country $i$, the government imposes an environmental tax $t_{i}$ per unit of pollutant emitted by the home firm $F_{i}$ and sets a tariff $\mu_{i}$ to regulate an imported good. So, tax and tariff revenues collected by the government in country $i$ are, respectively, $T_{i}=t_{i} d_{i}$ and $U_{i}=\mu_{i} e_{j}$.

The objective function of each government is to maximize social welfare $W_{i}$, which comprises the consumer surplus $C S_{i}$, the home firm's profit $\pi_{i}$, the tax and tariff revenues $T_{i}+U_{i}$ collected by the government, less the environmental damage $E D_{i}$ :

$$
W_{i}=C S_{i}+\pi_{i}+T_{i}+U_{i}-E D_{i},
$$

where the profit of firm $F_{i}$ is given by

$\pi_{i}=\left(\alpha-q_{i}\right) h_{i}+\left(\alpha-q_{j}\right) e_{i}-y_{i}^{2}-t_{i} d_{i}-\frac{a_{i}^{2}}{2}-\mu_{j} e_{i}, \quad i=1,2$

As in Wang and Wang [10], the public firm $F_{1}$ 's objective function is defined as the sum of consumer surplus and the firm's profit, given as $G=C S_{1}+\pi_{1}$.

The model has two stages. In the first stage, governments choose environmental taxes and import tariffs, simultaneously. Then, the firms engage in a Cournot competition, choosing output levels for the domestic market and to export, as well the pollution abatement levels.

By studying two cases, the mixed competition and the postprivatization competition, we show that, under the optimal environmental tax and import tariff, privatization of the home firm worsens domestic social welfare and improves social welfare in the country of the foreign firm; Furthermore, it results in an environmental improvement in both countries.

\section{Case I: Mixed duopoly}

In this section, we consider the case in which a home public firm $F_{1}$ competes with a foreign private firm $F_{2}$, according to the considerations above. Namely, the model consists in the following two-stages game:

-In the first stage, both home and foreign governments choose, simultaneously, environmental taxes $t_{1}$ and $t_{2}$, and import tariffs $\mu_{1}$ and $\mu_{2}$, respectively;

-In the second stage, both home public firm and foreign private firm choose, simultaneously, output levels for the domestic market, $h_{1}$ and $h_{2}$, and to export, $e_{1}$ and $e_{2}$, as well the pollution abatement levels, $a_{1}$ and $a_{2}$, respectively.

As usual, the game is solved by backwards induction. In the second stage, both firms choose, simultaneously, output and pollution abatement levels. So, we differentiate the function $G$ with respect to $h_{1}, e_{1}$ and $a_{1}$ and the function $\pi_{2}$ with respect to $h_{2}, e_{2}$ and $a_{2}$ :

$$
\frac{\partial G}{\partial h_{1}}=\alpha-2 e_{1}-3 h_{1}-t_{1}=0,
$$




$$
\begin{gathered}
\frac{\partial G}{\partial e_{1}}=\alpha-4 e_{1}-2 h_{1}-h_{2}-t_{1}-\mu_{2}=0, \\
\frac{\partial G}{\partial a_{1}}=t_{1}-a_{1}=0 \\
\frac{\partial \pi_{2}}{\partial h_{2}}=\alpha-e_{1}-2 e_{2}-4 h_{2}-t_{2}=0, \\
\frac{\partial \pi_{2}}{\partial e_{2}}=\alpha-4 e_{2}-h_{1}-2 h_{2}-t_{2}-\mu_{1}=0 \\
\frac{\partial \pi_{2}}{\partial a_{2}}=t_{2}-a_{2}=0 .
\end{gathered}
$$

The above first-order conditions yield the following results:

$$
\begin{gathered}
h_{1}=\frac{6 \alpha-5 t_{1}-t_{2}+\mu_{1}+6 \mu_{2}}{20}, \\
h_{2}=\frac{\alpha-t_{2}+\mu_{1}+\mu_{2}}{5} \\
e_{1}=\frac{2 \alpha-5 t_{1}+3 t_{2}-3 \mu_{1}-18 \mu_{2}}{40} \\
e_{2}=\frac{6 \alpha+5 t_{1}-11 t_{2}-29 \mu_{1}-14 \mu_{2}}{80}, \\
a_{1}=t_{1}, \quad a_{2}=t_{2} .
\end{gathered}
$$

From equations (7), we see that both home public and foreign private firms abate pollution to the point where marginal abatement costs equal the taxes.

In order to maximize the objective functions of the governments, we put (3-7) into $W_{1}$ and $W_{2}$, and then we differentiate $W_{1}$ with respect to $t_{1}$ and $\mu_{1}$ and $W_{2}$ with respect to $t_{2}$ and $\mu_{2}$ :

$$
\begin{gathered}
\frac{\partial W_{1}}{\partial t_{1}}=\frac{622 \alpha-4175 t_{1}+33 t_{2}+7 \mu_{1}-278 \mu_{2}}{1280}=0 \\
\frac{\partial W_{1}}{\partial \mu_{1}}=\frac{298 \alpha+35 t_{1}-653 t_{2}-3707 \mu_{1}-162 \mu_{2}}{6400}=0 \\
\frac{\partial W_{2}}{\partial t_{2}}=\frac{2082 \alpha+655 t_{1}-1985 t_{2}-1703 \mu_{1}+742 \mu_{2}}{6400}=0 \\
\frac{\partial W_{2}}{\partial \mu_{2}}=\frac{154 \alpha-365 t_{1}+371 t_{2}+309 \mu_{1}-2226 \mu_{2}}{3200}=0 .
\end{gathered}
$$

Thus, we obtain the following result ${ }^{1}$.

\footnotetext{
1 We use the superscript $M$ to refer to the mixed duopoly.
}

Proposition 1.At equilibrium, the environmental taxes and tariffs in the mixed duopoly are given by:

$$
\begin{array}{rlrl}
t_{1}^{M} & =\frac{295315 \alpha}{2034327}, & t_{2}^{M}=\frac{218053 \alpha}{2034327} \\
\mu_{1}^{M}=\frac{40518 \alpha}{678109}, & \mu_{2}^{M}=\frac{145532 \alpha}{2034327} .
\end{array}
$$

Now, substituting the previous values back to $a_{i}, h_{i}$ and $e_{i}$ yield the following outcomes at equilibrium:

Proposition 2.The pollution abatement levels in the mixed duopoly are, respectively, given by:

$$
a_{1}^{M}=\frac{295315 \alpha}{2034327}, \quad a_{2}^{M}=\frac{218053 \alpha}{2034327} .
$$

Proposition 3.The optimal quantities to be produced by each firm for the domestic market and for export in the mixed duopoly are, respectively, given by:

$$
\begin{array}{ll}
h_{1}^{M}=\frac{191768 \alpha}{678109}, & h_{2}^{M}=\frac{416672 \alpha}{2034327}, \\
e_{1}^{M}=\frac{6550 \alpha}{2034327}, & e_{2}^{M}=\frac{71518 \alpha}{2034327} .
\end{array}
$$

From this proposition, we get that the total production and consumption in the home country are

$$
y_{1}^{M}=\frac{25298 \alpha}{88449}, \quad q_{1}^{M}=\frac{646822 \alpha}{2034327}
$$

and the total production and consumption in the foreign country are

$$
y_{2}^{M}=\frac{162730 \alpha}{678109}, \quad q_{2}^{M}=\frac{141074 \alpha}{678109} .
$$

Also, from the results above, we obtain the profits of each firm, environmental damage level and the social welfare in each country, as shown below.

Proposition 4.At equilibrium, the environmental damage $E D_{i}^{M}$, the profit $\pi_{i}^{M}$ of each firm, and the social welfare $W_{i}^{M}$, in each country, in the mixed duopoly are given by:

$$
\begin{array}{rlrl}
E D_{1}^{M} & =\frac{9122733169 \alpha^{2}}{919663631762}, & E D_{2}^{M}=\frac{72973998769 \alpha^{2}}{8276972685858} \\
\pi_{1}^{M}=\frac{682115725913 \alpha^{2}}{8276972685858}, & \pi_{2}^{M}=\frac{881666822825 \alpha^{2}}{8276972685858} \\
W_{1}^{M}=\frac{66945275255 \alpha^{2}}{459831815881}, & W_{2}^{M}=\frac{61529140059 \alpha^{2}}{459831815881} .
\end{array}
$$


From this proposition, we conclude that, in equilibrium, the consumer surplus, the environmental damage and social welfare in the domestic country are higher than in the foreign country, which is due to the fact that the optimal total production and consumption are higher in the home country than in the foreign country. We also observe that, in equilibrium, the profit of home public firm is lower than that of the foreign private firm. This result is due to the fact that the domestic public firm acts to maximize home social welfare instead of its own profit, while the private foreign firm acts in order to maximize its own profit.

\section{Case II: Private duopoly (postprivatization)}

In this situation, both firms are assumed to be profit-maximizing private firms. So, the home firm $F_{1}$ aims now to maximize its own profit

$$
\pi_{1}=\left(\alpha-q_{1}\right) h_{1}+\left(\alpha-q_{2}\right) e_{1}-y_{1}^{2}-t_{1} d_{1}-\frac{a_{1}^{2}}{2}-\mu_{2} e_{1} .
$$

In the final stage, the firms produce the good in order to maximize their own profits. Using the same way of computations as previously, we get the following results ${ }^{2}$.

Proposition 5.At equilibrium, the environmental taxes and tariffs fixed by the governments in the privatized duopoly are given by:

$$
t_{i}^{P}=\frac{73 \alpha}{699}, \quad \mu_{i}^{P}=\frac{97 \alpha}{699} .
$$

From the above result, we have the following proposition.

Proposition 6.At equilibrium, the quantities to be produced by each firm for the domestic market and to export in the privatized duopoly are, respectively, given by:

$$
\begin{gathered}
h_{i}^{P}=\frac{131 \alpha}{699}, \quad e_{i}^{P}=\frac{34 \alpha}{699}, \\
a_{i}^{P}=\frac{73 \alpha}{699} .
\end{gathered}
$$

From this proposition, we get that the total production and consumption in each country are

$$
y_{i}^{P}=\frac{55 \alpha}{233}=q_{i}^{P} .
$$

Furthermore, we state the following

2 We use the superscript $P$ to refer to the private duopoly.
Proposition 7.At equilibrium, the environmental damage, the profit of each firm and the social welfare in each country in the privatized duopoly are, respectively, given by

$$
\begin{gathered}
E D_{i}^{P}=\frac{4232 \alpha^{2}}{488601}, \\
\pi_{i}^{P}=\frac{96413 \alpha^{2}}{977202}, \\
W_{i}^{P}=\frac{67601 \alpha^{2}}{488601} .
\end{gathered}
$$

\section{Effects of privatization}

In this section, we compare the mixed and privatized duopoly equilibria. The following result summarizes the effects of privatization.

Theorem 1.At equilibrium,

$$
\begin{gathered}
y_{i}^{P}<y_{2}^{M}<y_{1}^{M}, \\
q_{2}^{M}<q_{i}^{P}<q_{1}^{M}, \\
a_{i}^{P}<a_{2}^{M}<a_{1}^{M}, \\
t_{i}^{P}<t_{2}^{M}<t_{1}^{M}, \\
\mu_{1}^{M}<\mu_{2}^{M}<\mu_{i}^{P}, \\
\pi_{1}^{M}<\pi_{i}^{P}<\pi_{2}^{M}, \\
E D_{i}^{P}<E D_{2}^{M}<E D_{1}^{M}, \\
C S_{2}^{M}<C S_{i}^{P}<C S_{1}^{M}, \\
W_{2}^{M}<W_{i}^{P}<W_{1}^{M} .
\end{gathered}
$$

It is interesting to observe that privatization of a public firm raises tariffs and lowers environmental taxes in both countries. The last part of this sentence is natural, since it is expected that the more the competitive pressures, the stronger will be the incentive of the government to reduce the optimal tax in order to shift rent. The increase in the optimal tariffs leads to the decrease in the production level and, then, to the improvement in the environmental damage. We also note that privatization of the public firm decreases social welfare in the home country, but increases social welfare in the foreign country. This result is different from the one got by Ohori [6]. He has shown that privatization worsens social welfare in both countries.

Other effects of privatization are the following. In the home country, the profit of the home firm increases and the total consumption also increases. On the other hand, in the foreign country, the profit of the domestic firm decreases and the total consumption increases. 


\section{Comparisons: international versus domestic competition}

In this section, we will compare the results obtained in the international competition described above with the ones got by Wang and Wang [10], which consider a domestic competition.

They got the following result:

Proposition 8.[10] At equilibrium ${ }^{3}$,

$$
\begin{aligned}
\pi_{i}^{M, D} & <\pi_{i}^{P, D}, \\
E D^{M, D} & <E D^{P, D}, \\
W^{M, D} & <W^{P, D} .
\end{aligned}
$$

Thus, we can conclude that while privatization decreases environmental damage in the international competition studied in our paper, there is the opposite in the domestic competition. Furthermore, privatization also decreases the social welfare in the country of the public firm when an international competition is considered, in opposite result to the one verified on the domestic competition.

\section{Conclusions}

In this paper, we studied the effects of environmental and trade policies in an international duopoly serving two countries, with pollution abatement. The analysis was done in both mixed and privatized markets.

We concluded that, the private (resp., public) firm profits more (resp., less) in the mixed market than in the privatized one. Moreover, the environment is more damaged in the mixed duopoly than in the private market. Furthermore, in the mixed competition, the environment is more damaged in the country where the public firm is located than in the country of the private firm. The overall effect on the social welfare in the country of the public (resp., private) firm is that it will becomes higher (resp., lower) in the mixed than in the private market.

We also compared the privatization effects got in our international competition model with the ones observed in a domestic competition, and we concluded that they are different, when we look for the environmental damage and for the social welfare in the country where the public firm is located.

\section{Acknowledgement}

We thank Polytechnic Institute of Porto for its financial support.

\footnotetext{
3 We use the supersript $M, D$ (resp., $P, D$ ) to refer to the mixed (resp., private) duopoly, when both public and private firms are located in the same country.
}

\section{References}

[1] F. Ferreira, Privatization in an international mixed duopoly with environmental taxes, AIP Conf. Proc. 1648, 070003-1 070003-4 (2015).

[2] F. A. Ferreira, F. Ferreira, Privatization and government preferences in a mixed duopoly: Stackelberg versus Cournot, in Discontinuity and Complexity in Nonlinear Physical Systems, edited by J.A. Tenreiro Machado et al., Springer International Publishing Switzerland, 421-430 (2014).

[3] F. A. Ferreira, F. Ferreira, Privatization in a Mixed Duopoly with Environmental Taxes, AIP Conf. Proc. 1558, 1558-1561 (2013).

[4] K. Fjell, J. Heywood, Public Stackelberg leadership in a mixed oligopoly with foreign firms, Australian Economic Papers 41, 267-281 (2002).

[5] T. Matsumura, N. Matsushima, Endogenous cost differentials between public and private enterprises: A mixed duopoly approach, Economica 71, 671-688 (2004).

[6] S. Ohori, Environmental tax, trade, and privatization, Kyoto Economic Review 73, 109-120 (2004).

[7] D. Pal, M. White, Mixed oligopoly, privatization, and strategic trade policy, Southern Economic Journal 65, 264281 (2002).

[8] N. Serizawa, Optimal trade policy in an international mixed oligopoly, Seoul Journal of Economics 13, 107-122 (2000).

[9] Y. Tomaru, Privatization productive efficiency and social welfare with a foreign competitor, Research in Economics 61, 224-232 (2007).

[10] L. F. S. Wang, J. Wang, Environmental taxes in a differentiated mixed duopoly, Economic Systems 33, 389396 (2009).

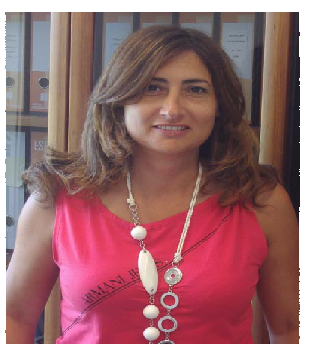

Fernanda A. Ferreira is a Professor at the School of Hospitality and Tourism of the Polytechnic Institute of Porto, Portugal. She earned $\mathrm{PhD}$ in Applied Mathematics from University of Porto. She has published journal and conference papers. Fernanda Ferreira is member of the Applied Management Research Unit (UNIAG). Her research interests include industrial organization and game theory. She is the author or co-author of more than 50 journal papers and conference proceedings. She has given talks in major international conferences, mainly on Mathematics and its applications in Engineering and Economics. 


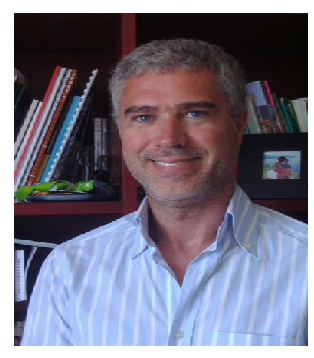

Flávio Ferreira is a Full Professor and the Dean of the School of Hospitality and Tourism of the Polytechnic Institute of Porto, Portugal. $\mathrm{He}$ earned $\mathrm{PhD}$ in Applied Mathematics from University of Porto. Flvio Ferreira is member of the Applied Management Research Unit (UNIAG). His research interests include industrial organization and game theory. He is co-author of a book published by Springer-Verlag, and author or co-author of more than 40 journal papers and conference proceedings. 